\title{
Overlapping identities: The role of village and occupational group for small-scale fishers' perceptions on environment and governance
}

\author{
Stefan Gehriga,b,*, Achim Schlüterb,c, Narriman S. Jiddawid \\ a Human Behaviour and Cultural Evolution Group, Department of Biosciences, University \\ of Exeter, Penryn Campus, UK \\ b Department of Social Sciences, Leibniz Centre for Tropical Marine Research (ZMT), \\ Bremen, Germany \\ c Department for Business \& Economics, Jacobs University, Bremen, Germany \\ d Institute of Marine Sciences, University of Dar es Salaam, Zanzibar, Tanzania
}

E-mail address: sg615@exeter.ac.uk (S. Gehrig).

This is the accepted manuscript of a paper originally published in Marine Policy. You may find the final, formatted version at 10.1016/j. marpol.2018.06.017.

\begin{abstract}
Resource users' perceptions are crucial for successful marine governance because they affect community support, participation and legitimacy. Efforts have been made to understand how fishers' attitudes, understandings and interpretations of the environment and its governance emerge in small-scale fisheries. However, many quantitative studies have focused on how individual-level attributes like socio-demographics are associated with perceptions, ignoring a fundamental scale at which humans arrive at their views about the world - the social group. In multi-gear fisheries, fishers typically cluster in two overlapping types of group: occupational groups (defined by fishing gear) and village communities. Taking into account also individuallevel variables, which group type is more associated with particular environmental and governance perceptions, e.g. about change in fish stocks, collective action or appropriate management actions? Through questionnaires in combination with multivariate and multi-model inference, this study reveals that, among fishers in two villages in Zanzibar $(n=172)$, village is more associated with perceptions than occupational group or any other factor. Further, individual attributes like education and age influence perceptions. The main finding implies that the role of social- cultural processes might have been underestimated in quantitative research on research users' perceptions. This has consequences for policy and research and shows that both can be informed by statistical analyses that disentangles effects of different levels of group belonging.
\end{abstract}




\section{Introduction}

Successful governance in small-scale fisheries requires community support, participation and legitimacy. Multiple frameworks like inter- active governance [14,42], the social-ecological systems approach [55], or (adaptive) co-management $[10,28]$ emphasise the need to under- stand and promote support of and involvement in management actions by local resource users. Support hinges a lot on what people think about and how people experience the system-to-be-governed and the governing system $[11,8]$. Consequently, a growing body of literature has been dedicated to the question of what shapes perceptions on environmental and governance processes and how this affects governance outcomes ${ }^{1}$ $[2,3,8,9,13,16,17,20,24,29-31,34,43,47,49,50,52,57,63,64]$. In this article, the term perceptions is used to cover the related concepts of attitudes (i.e., positive or negative evaluations and judgments), understandings (i.e., mental models of cause-effect relationships) and interpretations (i.e., awareness of and beliefs about the state of the world). Although these concepts are not used consistently in the literature and can overlap, our definition captures the basic idea that perceptions entail cognitiveinterpretive (how something is) and judgmental-normative (how something should be) dimensions $[11,8]$.

Perceptions constitute an important target for sustainability and conservation research for multiple reasons. For example, in the environmental psychology literature, pro-environmental behaviour is typically viewed as a result of intentions, which are themselves based on attitudes towards and awareness of environmental processes $[11,54,6]$. Turning to the marine environment, there is evidence from fishers [13] and national park visitors [2] that underlying perceptions are indeed associated with behaviour. Further, how coastal populations view the legitimacy of management measures as well as their social and ecological consequences affects acceptance and, ultimately, compliance behaviour $[44,66,9]$. On a larger scale, heterogeneity in perceptions on "how the resource is to be used and managed" has been shown to be negatively correlated with sustainability outcomes in a meta-analysis on fisheries commons [64]. Besides influencing behaviour, perceptions can be important proxies of well-being themselves. For example, fear of resource degradation may directly impair happiness and life satisfaction of resource users.

Hence, "[p]erceptions are an indispensable form of evidence that is useful at all stages of conservation from planning and implementation to ongoing management" ([8], p. 586). Though the importance of local resource users' environmental and management perceptions has been stressed repeatedly, it remains less clear which factors shape perceptions [11]. Arguably, this is of particular importance in fisheries, because the ecological environment is particularly uncertain, diverse and complex, and thus allows for strongly divergent interpretations and valuations across and within stakeholder groups $[35,48]$. It is widely acknowledged in the social sciences that social groups play a decisive role in the formation of attitudes, understandings and world views. Yet, surprisingly, many studies on perceptions of fishers focus primarily on how they are associated with individual-level attributes and exclude studying group variation by design or analysis (e.g., $[16,17,43,44,66])$. Whilst it is important to understand within-group variation arising from socio-economic or demographic differences, community-based governance is an inherently social endeavour and a "group behaviour" [11]. This requires to ask how perceptions differ not only between individuals, but also between social groups. ${ }^{2}$ There are good reasons to expect substantial

${ }^{1}$ This is not to say that perceptions are not themselves also outcomes of governance processes and interactions. They are continuously debated [42] and co-evolve with management actions [11,30].

${ }^{2}$ Note that the transition from individual-level to group-level characteristics is sometimes not treated rigorously in the literature on resource users' perceptions. For example, one can define "groups" through aggregating individuals by demographics, e.g., by level of education, age or wealth [43]. However, this article understands groups as defined by social and 
between-group variation at different societal scales.

Comparing groups might capture heterogeneity along more subtle dimensions that otherwise remains unobserved, because it is produced in group processes [11]. For example, social norms or "culturalcognitive institutions" [24] regarding resource use might differ between communities, while not being reflected in socio-economic or demo- graphic variables, but emerging from social and cultural learning within groups $[27,5,60]$. For example, Gelcich et al. [29] show be- tween-group variation in attitudes towards co-management between fishing cooperatives from different parts of Chile. Much of the variation remains unexplained by individual livelihood and socio-economic at- tributes alone. The authors suggest that social norms could play a role. A similar divergence of perceptions, unexplained by differences in socio-demographics like fishing experience or education, was found between Indonesian fishers from two different subdistricts [34]. Explicitly comparing individual- and group-level drivers among Philippine fishers, Chaigneau and Daw [13] demonstrate that village is an important predictor of attitudes towards protected areas which could not further be explained through observed individual attributes. They conclude that "community support needs to be understood at both an individual and a community scale" (p. 505), and call for more multi- level studies to properly understand how perceptions of resource users are formed. This is particularly important in contexts where people engage in multiple overlapping and nested groups simultaneously with potentially different cultures, habits and social identities $[11,12]$. This multidimensionality of social group membership is salient in multi-gear small-scale fisheries: fishers belong to a village community, but also to a group defined by the fishing gear they use. What do these two types of group belonging imply for fishers' environmental and governance perceptions?

Tackling this question, this study extends the conceptual scale of previous studies on perceptions and considers how a variety of environmental and governance perceptions are associated with factors on the individual level (socio-demographics), as well as on the level of two salient types of overlapping groups: the village community and the subgroup defined by the gear type. In accordance with Crona and Bodin [19], the latter will be referred to as the occupational group of a fisher. The selected study site is the inshore fisheries of Chwaka Bay in Zanzibar, Tanzania. As multi-gear, multi-species fishery, it is representative for many small-scale coastal resource systems in the Western Indian Ocean region [15,49]

The study area offers a unique window into the individual and group-level correlates of fishers' perceptions. Conflicting views are abundant between both occupational groups and villages in Chwaka Bay and threaten governability and long-term sustainability $[21,46]$. Both types of overlapping "communities", village and occupational group, have been identified as salient sources of identity, narratives and economic interests among fishers in the area in qualitative research [24,51]. Yet, to our knowledge, a systematic quantitative analysis of how heterogeneity in various environmental and governance perceptions is explained by one relative to the other type of group identity is missing, both for the local system and in similar multi-gear fisheries. That is the aim of this study.

economic organization with interaction and interdependence between its members $[11,67]$. 

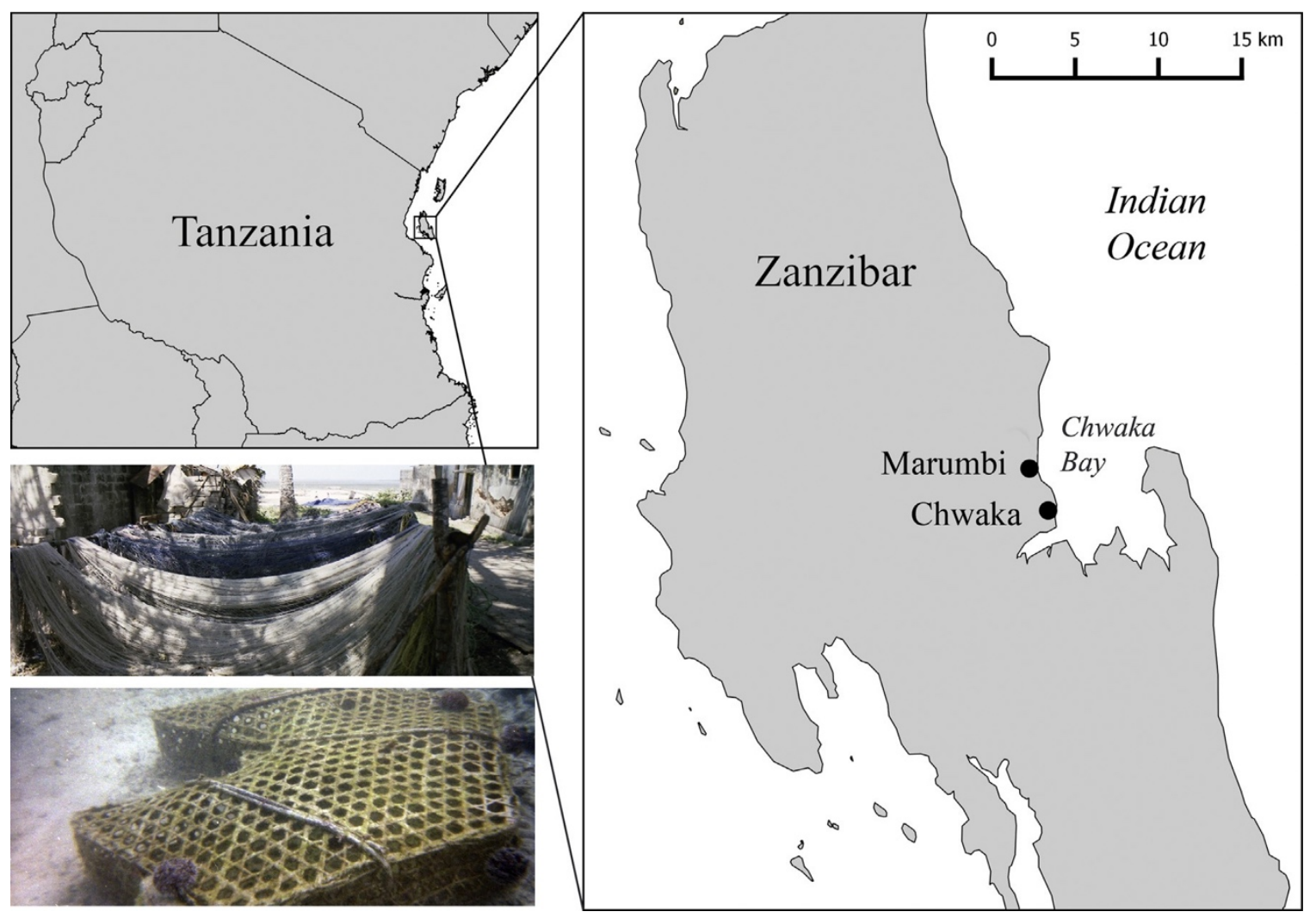

Fig. 1. Location of Chwaka Bay and the two study villages. The images show two of the most frequently used fishing gears in the area: nets (above; mainly in Chwaka) and basket traps (below; mainly in Marumbi).

\section{Local background and research questions}

This study examines various perceptions about the environment and human-environment interactions among two neighbouring fishing villages in Chwaka Bay, Zanzibar, Tanzania: Chwaka and Marumbi (Fig. 1). The Bay is a shallow-water ecosystem comprised of multiple productive habitats (seagrass meadows, mangrove forests, reef patches, tidal flats) which are the main source of local livelihoods. The area is rural and poverty is widespread. Fishing is the major occupation among men, while many women use the coastal habitats to collect in- vertebrates or to farm seaweed [26,33,37]. There are indications that coastal resources are over-exploited and long-term sustainability is under threat $[36,38,61]$. This has been attributed to the high dependence on fisheries resources, weak or misfitting governance institutions and the vulnerability of habitats to destructive fishing practices [24]. Gear and mesh size restrictions by the Department of Fishery and Marine Resources (DFMR) are in place, but are not effectively enforced $[21,22]$.

Socio-cultural heterogeneity between villages and groups of different gear types in the Bay is high and clashes between resource user groups have been abundant in the past [21,24,46,51]. A recurrent theme of disagreement is the exploitative and destructive use of dragnet techniques in seagrass meadows where fish 
recruitment takes place and where trap fishers employ their traditional, passive gear [25]. Dragnet fishing is exclusively carried out by fishers from Chwaka. However, also other gears are used in Chwaka (see Supplementary material for village distribution of gear types in the sample). This exemplifies how village and occupational group overlap in the area, which bears the interesting question which type of group identity plays a more important role in shaping perceptions - or, more generally, at which societal level people answer for themselves the fundamental questions of how a resource is to be used and managed.

Why should one expect village residency to have predictive power for perceptions? The role of the village belonging for marine governance perceptions, even when accounting for individual socio-economic characteristics, has been demonstrated previously [13]. Village captures emergent community-level processes that are hard to measure at the individual level (e.g., institutions, social learning, conformity, leadership), but also differences that might be due to geography (e.g., exposure to environmental factors). In the specific context of Chwaka Bay, institutional differences (e.g., regarding market participation, infrastructure, political orientation, or workplace organisation) are salient between villages [46,51], while biophysical conditions are rather similar due to the spatial proximity of the villages and the reliance on the same inshore fishing grounds (Fig. 1).

Why should one expect that, besides village-defined groups, perceptions should differ between occupational groups defined by gear type? Fishers from the same occupational group might be more likely to have similar perceptions due to relying on similar experience, know- how and skills in pursuing their fisheries livelihoods. They share habits and pay attention to the same aspects of the marine environment, which can influence perceptions [11]. Further, they share some economic and political interests, for example in particular species and habitats that are targeted by their fishing technology, and should thus favour certain regulations over others for the sake of income generation [49]. Such economic considerations have been shown to affect fishers' perceptions [31]. For example, co-management evaluation in artisanal barnacle fisheries in Spain differs between fishers that use different harvesting techniques [63]. The authors argue that the two occupational groups in diverge both in their "source of identity and attachment" and in their economic interests. There is also evidence that pat- terns of communication between artisanal fishermen cluster by fishing gear, leading to social networks that "consist of a number of subgroups communicating primarily with members of their own occupational category" [19], e.g. during joint fishing activities. As "face-to-face as well as mediated communications are essential in shaping perceptions and mutual understanding" ([11], p. 7), this could drive alignment of perceptions among people using the same fishing gear. ${ }^{3}$ In the specific context of Chwaka Bay, for example, different gear groups have been reported to rely on different understandings of sea tenure (with highly mobile net fishers ignoring customary fishing grounds that trap fishers still tend to acknowledge [24]), and to have different catch compositions [23,61], which could lead to divergence in management priorities.

The fact that gear choice in Chwaka Bay might also be subject to generational effects (i.e., age of the individual; [24]) and is associated with socio-economic variables like income [23] highlights the need for an analysis of perceptions that takes into account multiple levels and variables simultaneously and compares multiple statistical models, as presented in this paper.

Specifically, it is asked:

(1) What is the relative explanatory power of type of group identity (village and occupational group) and individual-level characteristics (socio-demographics) for a broad set of environmental and governance perceptions?

${ }^{3}$ Crona and Bodin [18] demonstrate that social networks of Kenyan small- scale fishers cluster by gear type and that this affects the distribution of local ecological knowledge. 
(2) Which characteristics are associated with which perceptions?

\section{Methods}

\subsection{Selection of perception variables and their predictors}

A set of ten environmental and governance perceptions that are important in the local context and that have been used in similar form in previous research were elicited (see Table 1). First, given the diversity and contested roles of different governance entities in the area [46], these encompassed questions on the importance of three different management institutions: the beach recorder [22], the village fishermen committees [15,32], and the DFMR. More generally, fishers were also asked whether the first step towards improving local conditions must be implemented from top-down ("by government") or bottomup ("by local people themselves"), a perception that is essential for the emergence of collective action and leadership [57]. Furthermore, perceptions on environmental change and appropriate interventions were elicited, because they attribute responsibility and thus, ultimately, drive community support for policies [11]. They were asked about the change of fish stocks in the last ten years, the ecological destructiveness of different fishing techniques, the main driver of resource degradation, the future of the Bay fisheries and the general vulnerability of the sea to overfishing.

Table 1

Description and summary statistics of perception (dependent) and predictor (independent) variables for all $\mathrm{n}=172$ fishermen from both sampled villages.

\begin{tabular}{|c|c|c|c|c|c|}
\hline Variable & Type & Description & $\begin{array}{l}\text { Mean (Std. } \\
\text { Dev.) }\end{array}$ & Min & Max \\
\hline \multicolumn{6}{|c|}{ Dependent variables: Perceptions } \\
\hline Imp. beach recorder & Continuous & Importance of beach recorder on scale from 1 (not at all) to 4 (very much) ${ }^{a}$ & $3.1(1.1)$ & 1 & 4 \\
\hline Imp. DFMR & Continuous & $\begin{array}{l}\text { Importance of Department of Fisheries and Marine Resources on scale from } 1 \text { (not at all) to } 4 \text { (very } \\
\text { much) }\end{array}$ & $2.9(1.1)$ & 1 & 4 \\
\hline Imp. committees & Continuous & Importance of village fishermen committees on scale from 1 (not at all) to 4 (very much) ${ }^{b}$ & $3.2(1.0)$ & 1 & 4 \\
\hline Fish stock change & Continuous & $\begin{array}{l}\text { Change in abundance of fish during last } 10 \text { years from }-1 \text { (decreased) over } 0 \text { (no change) to } 1 \\
\text { (increased) }\end{array}$ & $-0.6(0.8)$ & -1 & 1 \\
\hline Dragnet destructive & Binary & 1 if dragnet judged as most harmful fishing technique, 0 if other gear & 0.90 & - & - \\
\hline Future worry & Binary & 1 if worried about children having to use the same fishing grounds in the future, 0 otherwise & 0.74 & - & - \\
\hline Collective action & Binary & 1 if local people have to make the first step to improvement, 0 if the government & 0.37 & - & - \\
\hline Sea vulnerable & Binary & 1 if the sea is considered as vulnerable to overfishing, 0 if considered as always providing enough fish ${ }^{b}$ & 0.88 & _- & _- \\
\hline \multirow[t]{5}{*}{ Intervention type } & Categorical & Regulations & 0.13 & - & - \\
\hline & & Enforcement & 0.17 & - & - \\
\hline & & Education & 0.34 & - & - \\
\hline & & Equipment & 0.25 & - & - \\
\hline & & Alternative livelihoods & 0.10 & - & - \\
\hline \multirow[t]{3}{*}{ Main driver } & Categorical & Destructive fishing techniques & 0.77 & - & - \\
\hline & & Too much fishing & 0.19 & - & - \\
\hline & & Other (mentioned, e.g.: climate change) & 0.04 & - & - \\
\hline \multicolumn{6}{|c|}{ Independent variables: Predictors } \\
\hline Age & Continuous & Age in years & $36.0(14.1)$ & 16 & 90 \\
\hline Wealth & Continuous & First principal component from Principal Component Analysis on household items & $0.0(1.0)$ & -0.92 & 3.55 \\
\hline Poverty & Binary & 1 if daily income in any of the monsoon seasons falls below poverty line ( 1.90 USD), 0 atherxuse ${ }^{d}$ & 0.29 & - & - \\
\hline Education & Continuous & Formal education in years, including pursercx b & $9.3(3.3)$ & 0 & 17 \\
\hline Household size & Continuous & Number of people living in household & $5.8(2.3)$ & 2 & 13 \\
\hline Alternative occupations & Continuous & $\begin{array}{l}\text { Sum of (i) additional occupations held in household (other than fishing) and (ii) additional occupations } \\
\text { held by respondent within last five years (other than fishing) }\end{array}$ & $1.3(1.1)$ & 0 & 6 \\
\hline Boat & Binary & 1 if owns a boat alone or together with someone else, 0 otherwise & 0.49 & - & - \\
\hline Committee member & Binary & 1 if member of a village fishermen committee, 0 otherwise & 0.20 & - & - \\
\hline Net & Binary & 1 if dragnet $(n=14)$ or purse seine net $(n=18)$ is main gear, 0 otherwise & 0.19 & - & - \\
\hline Trap & Binary & 1 if basket trap is main gear, 0 otherwise & 0.58 & - & - \\
\hline Line & Binary & 1 if line is main gear, 0 otherwise & 0.13 & - & - \\
\hline Spear & Binary & 1 if spear $(n=14)$ or spear gun $(n=3)$ is main gear, 0 otherwise & 0.10 & - & - \\
\hline Fence & Binary & 1 if fence trap is main gear, 0 otherwise & 0.01 & - & - \\
\hline Village & Binary & 1 if village of residency is Chwaka 0 if Marumbi & 0.40 & - & - \\
\hline
\end{tabular}


As explained in Section 2, the main independent variables of interest were village residency and occupational group. While the former was straightforward to measure, the latter was defined by the fishers' self-reported main gear type. Although some fishers used multiple gear types, all could indicate a clear preference. Also, individual-level socio- demographic variables were included (age, education, wealth, poverty, household size, alternative occupations, boat, committee member; see Table 1 for explanations and summary statistics) that have been shown to be associated with perceptions in previous studies $[13,17,29,43]$.

Some independent variables require further explanation. Wealth was scored based on the first component of a varimax-rotated Principal Component Analysis on 18 household items [58] and mainly correlates with owning relatively advanced household items, such as a TV, fridge, DVD player or electricity, which were not owned by the majority (see Supplementary material). Instead of directly using daily income as a socio-economic variable, we used the self-reported daily income for both Monsoon seasons to arrive at a binary poverty variable, which was 1 if daily income in any season was below the United Nations poverty line of 1.90 USD (state: October 2015) and 0 otherwise. This was done because extreme poverty is pervasive in the area [23]. ${ }^{4}$ Fence trap was named as main gear type by only one respondent and was thus removed from all analyses where relevant. The Supplementary material reports the original survey questions. $^{5}$

\subsection{Data collection}

Data collection took place after a six week-period of extensive pilot interviews ( $\mathrm{n}=6$ fishers) and participant observation in the area by the first author. This was necessary to develop a fully structured questionnaire that fitted the local context and contained an appropriate set of multiple choice options. 172 male fishers were sampled from the two villages of Chwaka $(n=68)$ and Marumbi $(n=104)$ in November 2015 with the help of local contact persons (who did not know the aim of the study, but were advised to recruit from different occupational groups).

The sample size was constrained by research resources and, based on figures from Jiddawi [36], constitutes approximately $10 \%$ of all fishers from Chwaka and $40 \%$ of all fishers from Marumbi. Before the survey, all respondents had taken part in an incentivised economic experiment, which is not directly related to the research questions presented here and is reported elsewhere (in preparation). Data collection took place in local schools. The questionnaire took around 30 minutes per person. It was administered privately and anonymously (i.e., no name was re- corded). Trained local assistants read the questions out loud in Kiswa- hili and gave clarifications when needed. Assistants were not from the study villages. The order of survey questions was fixed and identical across respondents.

\subsection{Analysis}

\footnotetext{
${ }^{4}$ Poverty, defined in this way, was less closely correlated with wealth than income was, and thus likely captures an additional relevant socio-economic dimension.

${ }^{5}$ Some response options were grouped post hoc when the frequencies with which they were named were too low to allow robust analysis.
} 
All analysis was conducted in R [59]. Code and data for full re- production of the results are available on Code Ocean (https://doi.org/ 10.24433/CO.97578f41-f9a1-440f-aeb7-acbc70aeddb0). As a first step to distinguish variation explained by village from variation explained by occupational group, an analysis of similarity (ANOSIM) based on Bray-Curtis distances was conducted with each of the two candidate variables (village, occupational group), using the package vegan [53]. ANOSIM compares between-group and within-group similarity of responses (summarised in the test statistic $\mathrm{R}$ which is based on the difference of mean ranks between groups and within groups, see [53]) and provides a p-value based on permutations of the data $(n=1,000)$. Such multivariate approaches are appropriate for analysing many perceptions simultaneously without running multiple comparisons (e.g., [34]). As a next step, multimodel inference (package MuMIn; [7]) was used with an information theoretic approach based on AICc (a sample- size adjusted version of Akaike's information Criterion; see [68]) in order to identify the most important variables for the prediction of each perception variable. This procedure is advantageous to the selection of a single model and Null hypothesis testing when an analysis can be considered exploratory and when a multitude of plausible candidate models and observed variables exists $[13,68]$.

Specifically, a full model for each perception variable was fit using all predictors listed in Table 1 (when ignoring the negative correlations among the dummies for the occupational group, no pair of predictors was correlated with Pearson $r>0.55$, and the median correlation between predictors was $r=0.09$ ). All continuous predictors were standardised. Then, models were selected using the AICc criterion. The subset of best-fit models, defined as all models within $\triangle \mathrm{AICc}<1$ of the best model, was used for weighted model averaging to estimate coefficients and standard errors.

Relative Importance Values (RIVs) were calculated for each predictor, RIV constitutes the sum of AICc weights of all models in the subset in which the respective predictor occurs [68]. Thus, RIV ranges from 0 (the predictor occurs in none of the best-fit models) to 1 (the predictor occurs in all of the best-fit models) and represents the importance of a predictor for modelling a specific dependent variable, yet not the direction or size of an effect. It can be interpreted as the "probability that a predictor is a component of the best model" ([68], p. 17). We used linear, binomial and multinomial (package nnet; [69]) regressions for continuous, binary and categorical perception variables, respectively.

Apart from this "blind" multi-model inference to identify the best models, for each perception variable (i) a model with only the group variable (village or occupational group) as predictor and (ii) the single best model after removing the group variable was also fit. These two models allow to compare the explanatory power of the group alone with that of the combination of all other variables of the best model combined [13], yielding a complementary method of assessing their importance for perceptions. This procedure was applied both for village and occupational group.

\section{Results}

ANOSIM yielded a significant difference of perceptions when survey responses were grouped by village $(\mathrm{R}=0.15, \mathrm{p}<)$, but not when responses were grouped by occupational group, i.e., gear type $(\mathrm{R}=0.04, \mathrm{p}=$ 0.17; Fig. 2). This means that for village groups, but not for occupational groups, between-group dissimilarity of perceptions significantly exceeds within-group dissimilarity. The strong clustering by village and weaker clustering by occupational group is reflected in Fig. 2. 

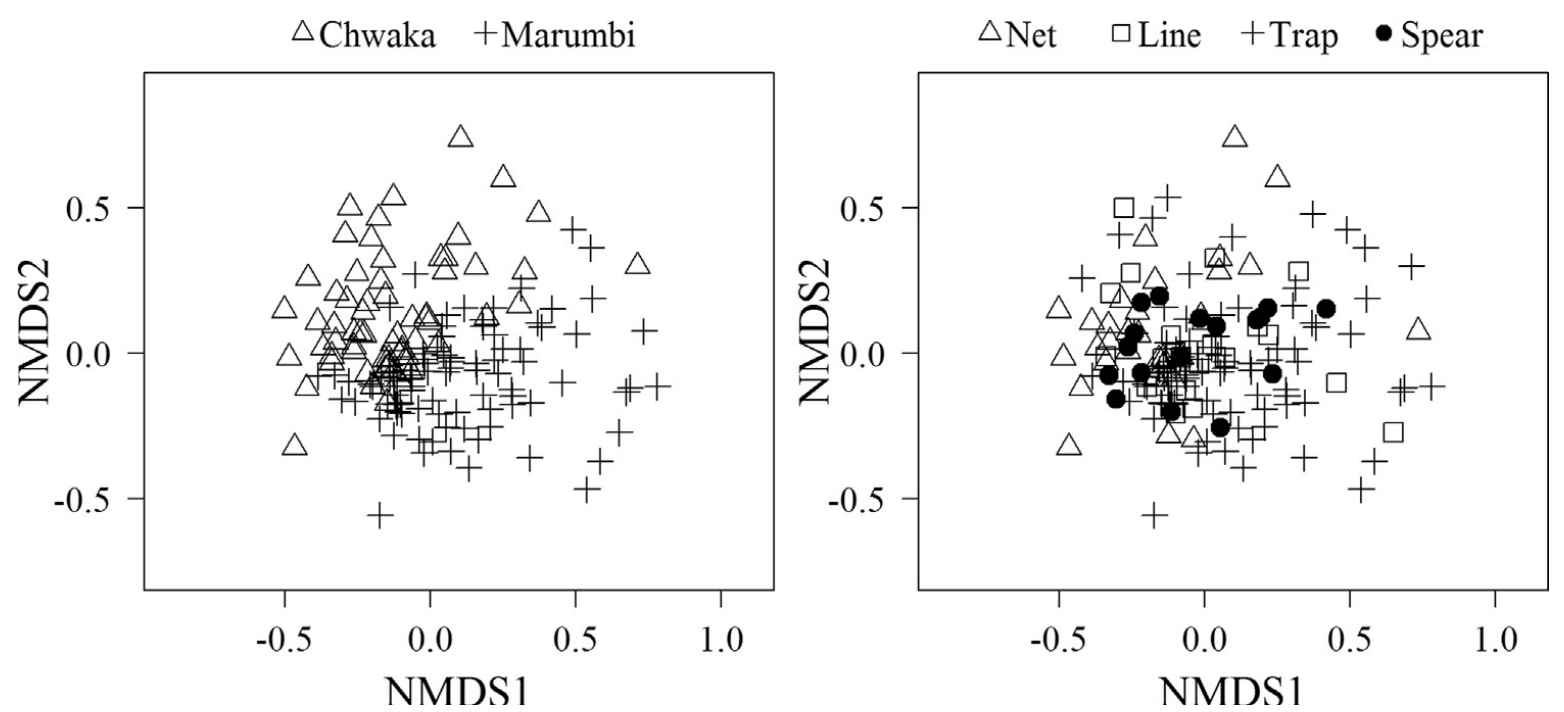

Fig. 2. Non-metric multidimensional scaling (NMDS) plots on clustering of perceptions by village (left) and occupational group (right), based on Bray-Curtis dissimilarity of survey responses.

Model selection and model averaging yielded RIVs for each pair of predictor and perception. In line with the results of ANOSIM, inspection of the plotted RIVs (Fig. 3) suggests that village is the single most important predictor across all perception variables (see concentration of bars at the village variable). The RIVs of the occupational groups are substantially lower, even when aggregated over all occupational groups (see Supplementary material for more details on the subset of best-fit models for each perception variable).

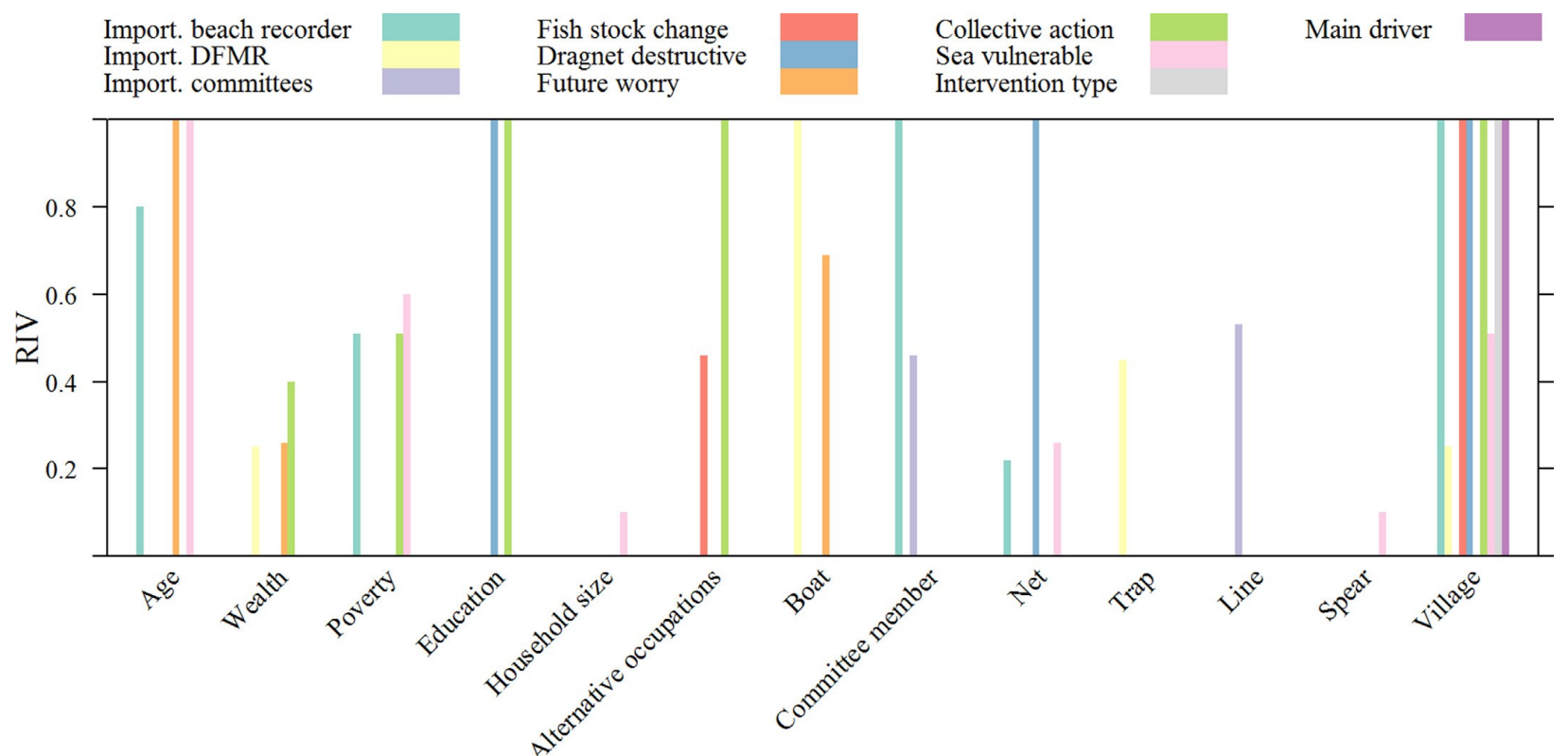

Fig. 3. Relative Importance Values (RIVs) for each pair of perception and predictor variable, based on the subset of best-fit models. From left to right, the order of predictors is individual attributes, occupational groups (net, trap, line spear) and village group. See Supplementary material for a corresponding table with all values presented in this Figure. 
For some perceptions, village has more predictive accuracy than all other variables of the best model combined (see positive $\Delta$ values in Table 2), which supports above results on the importance of village community in modelling perceptions. However, there are also cases, as for example regarding the attitude towards collective action, where village is a highly important predictor $(\mathrm{RIV}=1)$ and yet on its own is less explanatory than the other variables of the best model combined, in this case education, poverty and occupations. Thus, while village is the single most important factor to explain aggregated perception differences (Figs. 2 and 3), for some perceptions other factors matter more than village alone. In contrast, when turning to occupational groups instead of village, for no perception are they more predictive than the other variables of the best model combined, i.e., the AICc of a model with only occupational groups is always higher (indicating a worse fit) than the best-fit model after removing occupational groups as predictors (Table 2).

Table 2

Predictive power of group-level variables (village, occupational group). Shown are the AICc values of the best model for each perception variable (Best), for the best model without the respective group-level variable (Best without), and for a model with the respective grouplevel variable as the only predictor (Only). The rows labelled $\Delta$ show the difference between the latter two models for each perception variable, with positive values (in bold) indicating a better fit by the model with only the group-level variable than the best model without the group-level variable.

\begin{tabular}{|c|c|c|c|c|c|c|c|c|c|c|}
\hline & $\begin{array}{l}\text { Imp. beach } \\
\text { recorder }\end{array}$ & Imp. DFMR & $\begin{array}{l}\text { Imp. } \\
\text { committees }\end{array}$ & $\begin{array}{l}\text { Fish stock } \\
\text { change }\end{array}$ & $\begin{array}{l}\text { Dragnet } \\
\text { destructive }\end{array}$ & Future worry & $\begin{array}{l}\text { Collective } \\
\text { action }\end{array}$ & Sea vulnerable & Intervention type & Main driver \\
\hline \multicolumn{11}{|l|}{ Village } \\
\hline Best & 474.04 & 509.09 & 499.78 & 377.98 & 92.18 & 189.71 & 201.89 & 124.47 & 510.38 & 195.41 \\
\hline Best without & 515.31 & 509.09 & 499.78 & 400.45 & 101.06 & 189.71 & 212.06 & 124.47 & 532.15 & 227.73 \\
\hline Only & 478.13 & 513.6 & 500.94 & 377.98 & 98.04 & 199.35 & 216.92 & 130.47 & 510.38 & 195.41 \\
\hline$\Delta$ & 37.18 & -4.51 & -1.16 & 22.47 & 3.02 & -9.64 & -4.86 & -6.00 & 21.77 & 32.32 \\
\hline \multicolumn{11}{|c|}{ Occupational group } \\
\hline Best & 474.04 & 509.09 & 499.78 & 377.98 & 92.18 & 189.71 & 201.89 & 124.47 & 510.38 & 195.41 \\
\hline Best without & 474.04 & 509.09 & 500.16 & 377.98 & 97.19 & 189.71 & 201.89 & 124.47 & 510.38 & 195.41 \\
\hline Only & 509.87 & 517.01 & 505.49 & 401.40 & 106.14 & 203.89 & 228.98 & 136.39 & 542.59 & 218.49 \\
\hline Delta & -35.83 & -7.92 & -5.34 & -23.42 & -8.96 & -14.18 & -27.09 & -11.91 & -32.21 & -23.07 \\
\hline
\end{tabular}

Table 3 reports coefficients and standard errors from model aver- aging $(\triangle \mathrm{AICc}<1)$ of the most important predictors (RIV $>0.25$ ) for all perception variables. Village group is an important predictor for various perceptions. For example, living in Chwaka instead of Marumbi village is associated with on average 1 rating unit higher valuation of the beach recorder, a stronger view of fish stock decline by 0.56 units and only 0.08 times the odds of viewing dragnets as the most destructive fishing technique in the Bay. Chwaka fishers, as compared to Marumbi fishers, have a lower probability of perceiving that destructive fishing techniques are the main driver of environmental change relative to other drivers $(0.15$ times the odds) and a higher probability of perceiving that too much fishing is the main driver relative to other drivers (1.8 times the odds). Attitudes in Chwaka are more favourable towards collective action (3.6 times the odds). Also, they are more favourable towards interventions based on alternative livelihoods (8.2 times the odds) and new equipment (1.7 times the odds) and less favourable towards regulations ( 0.45 times the odds) and enforcement ( 0.25 times the odds; all relative to attitude towards intervention based on education).

For occupational group, there were fewer and smaller effects. The largest effect of any occupational group is observed for net fishers, who have only 0.2 time the odds of judging dragnet fishing as most destructive technique.

In addition to group-level variables contributing to the models with highest predictive accuracy, there are effects of individual-level characteristics (Fig. 3, Table 3). For example, being one standard deviation 
(SD) older (14 years) is associated with estimated 1.7 times the odds of worrying about the future of the fishing grounds and with 2.2 times the odds of viewing the sea as vulnerable instead of as an infinite provider of fish. This view on the exhaustibility of marine resources is also more likely to occur among fishers whose income falls below the poverty line ( 2.5 times the odds). Wealthier fishers report a more favourable attitude towards collective action: one SD increase in the wealth index is associated with 1.2 times the odds of perceiving that local people and not the government must undertake measures to improve the local situation. Wealthier fishers are also less likely to worry about the future of the fishing grounds ( 0.8 times the odds for one SD increase in the wealth index). People in village fishermen committees, as compared to people who are not, tend to disregard the importance of the beach recorder by approximately 0.4 rating units, while viewing committees as more important by approximately 0.3 rating units. Fishers who own a boat are more worried about the future of the fishing grounds (1.8 times the odds). More years of formal education are associated with being more likely to favour collective action (2.1 times the odds for an in- crease of one SD in formal education, which equals 3 years), just as with negative judgment of dragnet fishing (1.8 times the odds for an increase of one SD in education).

Table 3

Conditional averages of coefficients with standard errors from the models in the subset $\triangle \mathrm{AICc}<1$ for each perception variable. Coefficients for predictors with low importance $($ RIV $<0.25)$ are not reported. Note that coefficients need to be interpreted differently for linear, binomial and multinomial models and that continuous predictors (see Table 1) are standardised.

\begin{tabular}{|c|c|c|c|c|c|c|c|c|c|c|c|c|c|c|}
\hline & \multirow[b]{2}{*}{ Intercept } & \multicolumn{13}{|c|}{ Predictors } \\
\hline & & Age & Wealth & Poverty & Education & Household size & $\begin{array}{l}\text { Alternative } \\
\text { occupations }\end{array}$ & Boat & $\begin{array}{l}\text { Committee } \\
\text { member }\end{array}$ & Net & Trap & Line & Spear & Village \\
\hline Import. beach recorder & $2.82(0.11)$ & $\begin{array}{l}0.13 \\
(0.07)\end{array}$ & & $\begin{array}{l}-0.25 \\
(0.16)\end{array}$ & & & & & $-0.41(0.18)$ & & & & & $1.02(0.16)$ \\
\hline Imp. DFMR & $2.82(0.19)$ & & & & & & & $\begin{array}{l}0.40 \\
(0.17)\end{array}$ & & & $\begin{array}{l}-0.27 \\
(0.20)\end{array}$ & & & $\begin{array}{l}-0.30 \\
(0.19)\end{array}$ \\
\hline Imp. committees & $3.23(0.09)$ & & & & & & & & $0.26(0.20)$ & & & $\begin{array}{l}-0.36 \\
(0.24)\end{array}$ & & \\
\hline Fish stock change & $\begin{array}{l}-0.39 \\
(0.07)\end{array}$ & & & & & & $0.07(0.06)$ & & & & & & & $\begin{array}{l}-0.56 \\
(0.11)\end{array}$ \\
\hline Dragnet destructive & $4.40(0.80)$ & & & & $0.60(0.31)$ & & & & & $\begin{array}{l}-1.56 \\
(0.60)\end{array}$ & & & & $\begin{array}{l}-2.50 \\
(0.87)\end{array}$ \\
\hline Future worry & $0.96(0.27)$ & $\begin{array}{l}0.55 \\
(0.22)\end{array}$ & $\begin{array}{l}-0.18 \\
(0.17)\end{array}$ & & & & & $\begin{array}{l}0.61 \\
(0.38)\end{array}$ & & & & & & \\
\hline Collective action & $\begin{array}{l}-1.26 \\
(0.27)\end{array}$ & & $0.20(0.18)$ & $0.58(0.39)$ & $0.75(0.23)$ & & $0.42(0.19)$ & & & & & & & $1.29(0.37)$ \\
\hline Sea vulnerable & $1.93(0.33)$ & $\begin{array}{l}0.77 \\
(0.32)\end{array}$ & & $0.93(0.67)$ & & & & & & $\begin{array}{l}-1.03 \\
(0.70)\end{array}$ & & & & $0.89(0.62)$ \\
\hline Intervention type: Regulations ${ }^{\mathrm{a}}$ & $\begin{array}{l}-0.69 \\
(0.29)\end{array}$ & & & & & & & & & & & & & $\begin{array}{l}-0.79 \\
(0.57)\end{array}$ \\
\hline $\begin{array}{l}\text { Intervention type: } \\
\text { Enforcement }\end{array}$ & $\begin{array}{l}-0.33 \\
(0.26)\end{array}$ & & & & & & & & & & & & & $\begin{array}{l}-1.38 \\
(0.60)\end{array}$ \\
\hline Intervention type: Equipment & $\begin{array}{l}-0.54 \\
(0.27)\end{array}$ & & & & & & & & & & & & & $0.54(0.41)$ \\
\hline $\begin{array}{l}\text { Intervention type: Alternative } \\
\text { livelibeods } \sim\end{array}$ & $\begin{array}{l}-2.48 \\
(0.60)\end{array}$ & & & & & & & & & & & & & $2.10(0.69)$ \\
\hline Main driver: Too much fishigg ${ }_{n}^{b}$ & $3.87(0.71)$ & & & & & & & & & & & & & $\begin{array}{l}-1.90 \\
(0.86)\end{array}$ \\
\hline $\begin{array}{l}\text { Main driver: Destructive fishing } \\
\text { technigues }{ }^{\mathrm{b}}\end{array}$ & $1.10(0.82)$ & & & & & & & & & & & & & $0.59(0.95)$ \\
\hline
\end{tabular}

\section{Discussion}

This study quantitatively assessed artisanal fishers' perceptions about the coastal environment and its governance in a multi-gear, small-scale fishery in Chwaka Bay, Zanzibar, and how they were cor- related with different individual (socio-demographics) and group identity (village and occupational group). The results will be discussed with respect to the emergence of these perceptions and the implications for community-based management and governability. 


\subsection{Group effects}

The majority of environmental and governance perceptions were well explained by village residency, and to a much lesser extent by occupational group (gear types). Village groups, but not occupational groups, (i) had significantly higher between-group than within-group variation in aggregated perceptions (ANOSIM; Fig. 2), (ii) appeared in the best-fit models for almost all perceptions (Fig. 3) and (iii) had higher predictive accuracy (lower AICc) than the rest of the variables of the best-fit models combined for various perceptions (Table 2). This finding is in line with other studies that found natural resource users' attitudes vary across different groups like village community, fishing cooperative, occupational, stakeholder or ethnic groups $[13,29,47,49,52,57]$. However, this study adds another layer to the analysis, by considering two different types of group simultaneously that overlap in the study area and that are likely important for individuals' socio-economic conditions and their social identity [21,23,24,46,51]. There are many ways to define "community" in natural resource-use contexts [1], and the results presented here suggest that the relevant level of segregation of attitudes, understandings and interpretations among Chwaka Bay's fishers is the village level, not the level of the occupational group.

This is surprising for at least two reasons. First, occupational groups in Chwaka Bay have been reported to carry specific normative and cultural-cognitive framings of the fishing occupation which are exacerbated through a "sense of group belonging" [24]. Second, their economic practices (where, when, what, with whom and with how many people they fish) and outcomes (seasonal incomes and expenditures) differ $[23,61]$. Both should affect perceptions of, for ex- ample, preferred management actions. This is easy to see for net fishers, whose income would suffer under stronger enforcement of the current restrictions on net use in the Bay. However, only village was found to be related to perceptions on management actions. Even when considering attitudes towards the destructiveness of dragnet fishing, where gear type has some explanatory power in the sense that people who use nets (all of which can be used for dragging) are less concerned about their impacts ${ }^{6}$ (as also found among Kenyan fishers by McClanahan et al. [49]), village has the strongest effect size. Whereas almost all fishers attributed environmental change in their area to human behaviour $(97 \%$, as opposed to perceived reasons outside human control like cli- mate change), fishers in Chwaka village ascribe it more to overall fishing pressure and less to destructive techniques. Remaining un- changed, this divergence of views can obstruct Baylevel governance because "[w]here responsibility is placed can make a significant difference regarding future behaviour change and participation" ([11], p. 4).

How can the substantial village effect on perceptions be explained, given that the two villages are located in close geographical proximity, are subject to very similar biophysical conditions, similarly depend on fishing as the major livelihood and lack obvious cultural differences with respect to religion, ethnicity or language? There are multiple non- exclusive explanations, which probably contribute to the results to different degrees.

First, there are methodological issues. The results are probably de- pendent on the set of perceptions that are included in the survey, be- cause different perceptions are more or less clustered by village (Fig. 3). However, this would be true for any selected dependent variables, and the variables in this study were selected with respect to relevance for local resource governance. Second, since the analysis is purely correlational, it is not a priori clear if fishers self-selected into villages by migrating to peers with similar perceptions. Yet, the effect is likely to be small, because only $16 \%$ of fishers in the sample had ever

\footnotetext{
${ }^{6}$ The causality might either go the way that such perceptions induce fishers to take up these gears, or that the use of nets leads to motivated reasoning, i.e. to environmental attitudes that are biased in a self-serving manner [41].
} 
changed village residency. Third, village captures unobserved heterogeneity in individual attributes that is not accounted for by the predictors chosen in this study (as discussed similarly in [34]). This unobserved heterogeneity can be of two types.

On the one hand, there can be important unobserved variation in individual attributes, which could be caused by mere exposure to geographical, ecological or policy factors that vary on the level of the village and affect all fishers individually (e.g., in Chwaka, but not in Marumbi, the governmental beach recorder is active on the landing site and visible to all fishers on a daily basis, which probably contributes to the higher importance ratings by individuals in the former community).

On the other hand, heterogeneity can be the result of emergent "community scale factors and processes", as Chaigneau and Daw [13] suggested for the perceptions in their sample of Philippine fishers. Similar to us, they propose that interactive social processes on the level of the village group lead to observable differences between communities, rather than pure aggregation of individual differences (see also [67]). Group processes, rather than just shared characteristics, can be essential in the formation of attitudes, understandings and interpretations in marine governance [11]. Based on knowledge of the study site, emergent social-cultural factors probably play a significant role. Institutional differences between villages in Chwaka Bay are large [24,51], and social norms with respect to economic workplace organisation, kinship relations or technology endorsement have diverged between the two study villages within the last decades as a result of differential development and modernization $[21,56]$. These processes are not fully captured by easily observable individual differences. Although rather implicitly, emergent group-level processes have been discussed previously in the literature on resource governance. For example, local leaders, or "sense-makers", can guide the spread of attitudes and world views in communities [72], or conformity and traditional social norms might obstruct the formation of attitudes that are conducive to social-ecological resilience ([73], p. 127-129).

Why should people learn and adopt views that are similar to those of their village peers and neighbours, but are not necessarily accurate or in their own interest? The theory of "expressive rationality" argues that there are important psychological, and, ultimately, material benefits from conforming to the beliefs and perceptions of one's close social group [39]. Against the background of the data presented here, village could be the most salient and important type of identity for fishers in the study area (at least from the two dimensions of identity assessed in this study) and, thus, village-belonging could be maintained by cultural, "identity-protective cognition" [40]. This mirrors qualitative findings from the area which emphasise the clash of "cultural-cognitive institutions" between villages and occupational groups [24]. However, we find village to be far important in shaping perceptions than occupational group. A reason could be that village identity is "learned" prior to occupational category in a fisher's lifespan, and that interactions with fellow villagers are more frequent and important than with people from the same occupational group.

This line of thought demonstrates the immense value of incorporating culture, even on the small scale of the community, as "an important variable mediating the relationship between humans and the natural environment" ([12], p. 8158) into the study of resource users' perceptions and community support, especially when acknowledging that culture can exist simultaneously across multiple overlapping group identities [12].

Among suitable instruments to enhance mutual understanding and shape a common world view be participatory arenas that consist of different stakeholders from different communities, ideally built through democratic processes and with political and scientific support. In this spirit, it has also been argued that "perception experts" can support community-based management by engaging in reflection and communication across attitudinal group boundaries [11]. This could enable collective learning on a higher level [4] and thus give halt to the on- going divergence of perceptions. In the study area, the reconciliation 
of institutions and perceptions on the scale of the Bay might require hierarchical and top-down efforts, because currently self-organization remains mostly restricted to villages and occupational groups [46]. This study shows that village might be the most important societal level at which common ground is lacking. If resource user will be able to receive and perceive benefits from Bay-level, rather than villagelevel action, e.g., in the form of increased long-term catches, this might shift the relevant level at which institutions, as well as attitudes and perceptions, emerge from villages up to the social-ecological

system $[70,71] .^{7}$

\subsection{Other effects}

Apart from village and occupational group, some individual variables bear predictive power for perceptions among fishers as well. Consistent with previous qualitative work in the area, which discussed intergenerational conflicts [24], there are effects of age on perceptions. This study shows that older fishers are more worried about the future of the fishing grounds and more likely to perceive the sea as a finite and vulnerable source of fish. This is in line with the work of Alessa et al.[3] who found perceptions on ecological change in the Arctic to be particularly severe among elderly fishers. This could imply that more experienced fishers are a valuable source of ecological awareness against the threat of shifting baselines [65]. In Indonesia, more experienced fishers have been found to put more value on environmental protection than income relative to younger age groups [34]. Nevertheless, older fishers in Chwaka Bay might be particularly vulnerable and have low adaptive capacity: age correlates with higher incidence of poverty $(\mathrm{r}=0.10)$ and less education $(\mathrm{r}=-0.52)$ in the sample, factors that complicate exiting a declining fishery or initiating change [16].

Indeed, it was found that higher education is associated with the perception that dragnet fishing is most destructive and that bottom-up collective action is important to improve the local situation. Thus, there is higher perceived threat and perceived behavioural control on this environmental issue among more educated fishers. Both have been shown to be precursors for transformative behaviour (e.g., [54]). Education can lead to more pro-environmental perceptions and more positive attitudes towards comanagement interventions [44]. Empowerment through education should thus be prioritised. So far, recognition of the importance of collective action is low among fishers in the sample of this study (37\%), compared to, for example, results from Mexican fishing communities where a similar question was asked (73\%; [57]).

Finally, being in a fishermen committee is (weakly) linked to particular perceptions. Cinner et al. [15] describe these committees as "government supported, community-based organizations that operate at a village level under the supervision of the village head and government fisheries officers". The results show that being a member of a fishermen committee is associated with a higher rating of their importance, but a lower rating of the importance of the beach recorder. This "self-serving" attitude is surprising, given that committees and beach recorder are both meant to work in concert with government agencies [15].

\footnotetext{
${ }^{7}$ Apart from these interventions that focus on support, participation and legitimacy, recent work by Rehren [61] suggests that suitable management options in the area encompass (i) decreasing dependence on destructive fishing methods, (ii) spatial closures, (iii) accessing new off-shore fishing grounds, and, most importantly, (iv) diversifying livelihoods. In line with the importance of perceptions and community support emphasised here, she notes that " $[t]$ he fishing community must be involved in setting such fishing effort reduction.".
} 
This highlights the need to align and integrate the agenda and scale of various governance entities under a unifying theme and world view (i.e., meta-governance; $[42,46]$ ).

\section{6. $\quad$ Future directions}

This study provided evidence for the role of the village community in shaping perceptions on the systemto-be-governed and the governing system in small-scale fisheries. Since this can be interpreted as at least partially resulting from socio-cultural village-level processes, the finding encourages more research on how multi-level cultural evolution affects sustainable governance $[62,70,71]$, and generally on the role of group processes for perceptions in marine governance [11]. Within- and between-group social dynamics might play a larger role for the spread of attitudes, understandings and interpretations than acknowledged in some previous research on the role of individual characteristics for fishers' perceptions $[16,17,42,43,66]$. Settings as presented in this paper, where multiple types of "communities", or group identities, co- exist and overlap, can be ideal sites to study more in detail, e.g., longitudinally, how social dynamics shape world views. There are limitations to the research presented here that further studies could address. For example, based on the rationale to focus on fishers, we sampled exclusively men, although women's activities in Chwaka Bay, as in all small-scale fisheries, are both socially and ecologically significant [26,33]. Also, by expanding the set of individual-level predictors (e.g., including psychological characteristics; [11]), further re- search might be able to reduce the amount of unobserved heterogeneity and thus to more clearly identify group and socio-cultural processes as drivers of perceptions. Our study design is not able to resolve which factors and processes associated with village identity drive perceptions. For arriving at a clearer picture of which social dynamics at which scales shape perceptions, tools like social network analysis could prove extremely helpful [19], as they might be able to track learning and communication. This is relevant for resource governance particularly in developing regions where the state often plays only a weak role and mostly informal institutions and group relations govern resource use. Also, the link between perceptions and actual behaviour needs to be established further $[13,2,27,45]$, just as how both co-evolve with co- management $[11,30]$.

\section{Acknowledgments}

We thank the people and village heads of the two communities for making the research possible. We are very grateful for the great work by our field assistants Ramadhan Rashid, Saidi Juma, Amin Omar and Mkanga Ali. The work profited very much from discussions with Jennifer Rehren. Funding was provided by the Leibniz Association (SAW-2013-ZMT-4 234) within the project Sustainable Use of Tropical Aquatic Systems (SUTAS).

\section{Competing interests}

The authors declare that they have no competing interests.

Appendix A. Supplementary material

Supplementary data associated with this article can be found in the online version at doi:10.1016/j.marpol.2018.06.017. 


\section{References}

[1] A. Agrawal, C.C. Gibson, Enchantment and disenchantment: the role of community in natural resource conservation, World Dev. 27 (1999) 629-649.

[2] L. Alessa, S.M. Bennett, A.D. Kliskey, Effects of knowledge, personal attribution and perception of ecosystem health on depreciative behaviors in the intertidal zone of Pacific Rim National Park and Reserve, J. Environ. Manag. 68 (2003) 207-218.

[3] L. Alessa, A.D. Kliskey, P. Williams, M. Barton, Perception of change in freshwater in remote resource-dependent Arctic communities, Glob. Environ. Change 18 (2008) 153-164.

[4] D. Armitage, M. Marschke, R. Plummer, Adaptive co-management and the paradox of learning, Glob. Environ. Change 18 (2008) 86-98, https://doi.org/10.1016/j. gloenvcha.2007.07.002.

[5] S. Atran, D.L. Medin, N.O. Ross, The cultural mind: environmental decision making and cultural modeling within and across populations, Psychol. Rev. 112 (2005) 744.

[6] S. Bamberg, G. Möser, Twenty years after Hines, Hungerford, and Tomera: a new meta-analysis of psycho-social determinants of pro-environmental behaviour, $\mathrm{J}$. Environ. Psychol. 27 (2007) 14-25.

[7] K. Barton, MuMIn: Multi-Model Inference, 2016.

${ }_{[8]}$ N.J. Bennett, Using perceptions as evidence to improve conservation and environmental management: perceptions and conservation, Conserv. Biol. 30 (2016) 582592, https://doi.org/10.1111/cobi.12681.

[9] N.J. Bennett, P. Dearden, Why local people do not support conservation: commu- nity perceptions of marine protected area livelihood impacts, governance and management in Thailand, Mar. Policy 44 (2014) 107-116.

[10] F. Berkes, Evolution of co-management: role of knowledge generation, bridging organizations and social learning, J. Environ. Manag. 90 (2009) 1692-1702, https://doi.org/10.1016/j.jenvman.2008.12.001.

[11] K. Beyerl, O. Putz, A. Breckwoldt, The role of perceptions for community-based marine resource management, Front. Mar. Sci. 3 (2016) 238.

[12] M.M. Caldas, M.R. Sanderson, M. Mather, M.D. Daniels, J.S. Bergtold, J. Aistrup, J.L.H. Stamm, D. Haukos, K. Douglas-Mankin, A.Y. Sheshukov, et al., Opinion: endogenizing culture in sustainability science research and policy, Proc. Natl. Acad. Sci. USA 112 (2015) 8157-8159.

[13] T. Chaigneau, T.M. Daw, Individual and village-level effects on community support for marine protected areas (MPAs) in the Philippines, Mar. Policy 51 (2015) 499506, https://doi.org/10.1016/j.marpol.2014.08.007.

[14] R. Chuenpagdee, S. Jentoft, Governability assessment for fisheries and coastal systems: a reality check, Hum. Ecol. 37 (2009) 109-120.

[15] J.E. Cinner, T.M. Daw, T.R. McClanahan, N. Muthiga, C. Abunge, S. Hamed, B. Mwaka, A. Rabearisoa, A. Wamukota, E. Fisher, N. Jiddawi, Transitions toward co-management: the process of marine resource management devolution in three east African countries, Glob. Environ. Change 22 (2012) 651-658, https://doi.org/ 10.1016/j.gloenvcha.2012.03.002.

[16] J.E. Cinner, C. Folke, T. Daw, C.C. Hicks, Responding to change: using scenarios to 
understand how socioeconomic factors may influence amplifying or dampening exploitation feedbacks among Tanzanian fishers, Glob. Environ. Change 21 (2011) 7-12, https://doi.org/10.1016/j.gloenvcha.2010.09.001.

[17] J.E. Cinner, R.B. Pollnac, Poverty, perceptions and planning: why socioeconomics matter in the management of Mexican reefs, Ocean Coast. Manag. 47 (2004) 479493, https://doi.org/10.1016/j.ocecoaman.2004.09.002.

[18] J.E. Cinner, Poverty and the use of destructive fishing gear near east African marine protected areas, Environmental Conservation 36 (4) (2009) 321-326.

[19] B. Crona, Ö. Bodin, What you know is who you know? Communication patterns among resource users as a prerequisite for co-management, Ecol. Soc. (2006) 11.

[20] T.M. Daw, J. Robinson, N.A. Graham, Perceptions of trends in Seychelles artisanal trap fisheries: comparing catch monitoring, underwater visual census and fishers' knowledge, Environ. Conserv. 38 (2011) 75-88.

[21] M. de la Torre-Castro, Management challenges in Chwaka Bay, Zanzibar, Tanzania: historical development and future prospects, in: M. de la Torre-Castro, T.J. Lyimo

(Eds.), Zanzibar Town, 2012, pp. 279-302.

[22] M. de la Torre-Castro, Beyond regulations in fisheries management: the dilemmas of the "beach recorders" Bwana Dikos in Zanzibar, Tanzania, Ecol. Soc. 11 (2006) 35.

[23] M. de la Torre-Castro, G. Di Carlo, N.S. Jiddawi, Seagrass importance for a smallscale fishery in the tropics: the need for seascape management, Mar. Pollut. Bull. 83 (2014) 398-407, https://doi.org/10.1016/j.marpolbul.2014.03.034.

[24] M. de la Torre-Castro, L. Lindström, Fishing institutions: addressing regulative, normative and cultural-cognitive elements to enhance fisheries management, Mar. Policy 34 (2010) 77-84, https://doi.org/10.1016/j.marpol.2009.04.012.

[25] M. de la Torre-Castro, P. Rönnbäck, Links between humans and seagrasses-an example from tropical East Africa, Ocean Coast. Manag. 47 (2004) 361-387.

[26] J.S. Eklöf, F.E. Msuya, T.J. Lyimo, A.S. Buriyo, Seaweed farming in Chwaka Bay: a sustainable alternative in aquaculture, in: M. De la Torre-Castro, T.J. Lyimo (Eds.), People, Nature and Research in Chwaka Bay, WIOMSA, Zanzibar, 2012, pp. 213233.

[27] Á. Fernández-Llamazares, I. Díaz-Reviriego, M. Guèze, M. Cabeza, A. Pyhälä, V. Reyes-García, Local perceptions as a guide for the sustainable management of natural resources: empirical evidence from a small-scale society in Bolivian Amazonia, Ecol. Soc.: J. Integr. Sci. Resil. Sustain. (2016) 21.

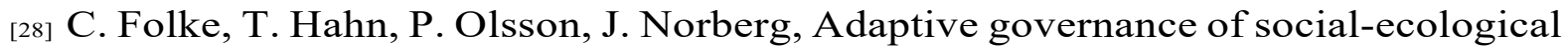
systems, Annu. Rev. Environ. Resour. 30 (2005) 441-473, https://doi.org/10. 1146/annurev.energy.30.050504.144511.

[29] S. Gelcich, G. Edwards-Jones, M.J. Kaiser, Importance of attitudinal differences among artisanal fishers toward co-management and conservation of marine resources, Conserv. Biol. 19 (2005) 865-875.

[30] S. Gelcich, M.J. Kaiser, J.C. Castilla, G. Edwards-Jones, Engagement in co-management of marine benthic resources influences environmental perceptions of artisanal fishers, Environ. Conserv. (2008) 35, https://doi.org/10.1017/ S0376892908004475.

[31] P. Gorris, Deconstructing the reality of community-based management of marine 
resources in a small island context in Indonesia, Front. Mar. Sci. 3 (2016) 120.

[32] M. Gustavsson, L. Lindström, N.S. Jiddawi, M. De La Torre-Castro, Procedural and distributive justice in a community-based managed marine protected area in Zanzibar, Tanzania, Mar. Policy 46 (2014) 91-100.

[33] E. Håkansson, S. Fröcklin, M. De La Torre-Castro, Invertebrate collection in Chwaka village: importance, gender and resilience aspects, in: M De la Torre-Castro, T.J. Lyimo (Eds.), People, Nature and Research in Chwaka Bay, WIOMSA, Zanzibar, 2012, pp. 234-265.

[34] E. Hoshino, E.I. van Putten, W. Girsang, B.P. Resosudarmo, S. Yamazaki, Fishers' perceived objectives of community-based coastal resource management in the Kei Islands, Indonesia, Front. Mar. Sci. 4 (2017) 141.

[35] S. Jentoft, R. Chuenpagdee, Fisheries and coastal governance as a wicked problem, Mar. Policy 33 (2009) 553-560.

[36] N. Jiddawi, Artisanal fisheries and other marine resources in Chwaka Bay, in: M. de la Torre-Castro, T.J. Lyimo (Eds.), People, Nature and Research in Chwaka Bay, Zanzibar, Tanzania, Zanzibar Town, 2012, pp. 193-212.

[37] N. Jiddawi, L. Lindström, Physical characteristics, socio-economic setting and coastal liveilhoods in Chwaka Bay, in: M. de la Torre-Castro, T.J. Lyimo (Eds.), People, Nature and Research in Chwaka Bay, Zanzibar, Tanzania, Zanzibar Town, 2012, pp. 23-40.

[38] N.S. Jiddawi, M.C. Öhman, Marine fisheries in Tanzania, AMBIO: J. Hum. Environ. 31 (2002) 518-527, https://doi.org/10.1579/0044-7447-31.7.518.

[39] D.M. Kahan, The expressive rationality of inaccurate perceptions, Behav. Brain Sci. (2017) 40.

[40] D.M. Kahan, Ideology, Motivated Reasoning, and Cognitive Reflection: An Experimental Study, Judgment and Decision Making 8 (2013) 407-424 (November 29, 2012).

[41] E. Kals, J. Maes, Sustainable development and emotions, Psychol. Sustain. Dev. (2002) 97-122.

[42] J. Kooiman, M. Bavinck, R. Chuenpagdee, R. Mahon, R. Pullin, et al., Interactive governance and governability: an introduction, J. Transdiscipl. Environ. Stud. 7 (2008) 1-11.

[43] J.D. Lau, C.C. Hicks, G.G. Gurney, J.E. Cinner, Disaggregating ecosystem service values and priorities by wealth, age, and education, Ecosyst. Serv. 29 (2018) 91-98.

[44] C.C. Launio, Y. Morooka, H. Aizaki, Y. Iiguni, Perceptions of small-scale fishermen on the value of marine resources and protected areas: case of Claveria, northern Philippines, Int. J. Sustain. Dev. World Ecol. 17 (2010) 401-409.

[45] S. Li, L. Juhász-Horváth, P.A. Harrison, L. Pintér, M.D. Rounsevell, Relating farmer's perceptions of climate change risk to adaptation behaviour in Hungary, J. Environ. Manag. 185 (2017) 21-30.

[46] L. Lindström, M. de la Torre-Castro, Promoting governability in small-scale fisheries in Zanzibar, Tanzania: from self-governance to co-governance, in: J. Svein, C. Ratana (Eds.), Interactive Governance for Small-Scale Fisheries, Springer, Dodrecht, 2015, pp. 671-686.

[47] L. Loft, D.N. Le, T.T. Pham, A.L. Yang, J.S. Tjajadi, G.Y. Wong, Whose equity 
matters? National to local equity perceptions in Vietnam's payments for forest ecosystem services scheme, Ecol. Econ. 135 (2017) 164-175.

[48] R. Mahon, P. McConney, R.N. Roy, Governing fisheries as complex adaptive systems, Mar. Policy 32 (2008) 104-112.

[49] T.R. McClanahan, J. Maina, J. Davies, Perceptions of resource users and managers towards fisheries management options in Kenyan coral reefs, Fish. Manag. Ecol. 12 (2005) 105-112.

[50] J.N. Mehta, S.R. Kellert, Local attitudes toward community-based conservation policy and programmes in Nepal: a case study in the Makalu-Barun conservation area, Environ. Conserv. 25 (1998) 320-333.

[51] G.A. Myers, Local communities and the new environmental planning: a case studyfrom Zanzibar, Area 34 (2002) 149-159.

[52] V. Nazarea, R. Rhoades, E. Bontoyan, G. Flora, Defining indicators which make sense to local people: intra-cultural variation in perceptions of natural resources, Hum. Organ. 57 (1998) 159-170.

[53] J. Oksanen, F.G. Blanchet, M. Friendly, R. Kindt, P. Legendre, D. McGlinn, P.R. Minchin, R.B. O'Hara, G.L. Simpson, P. Solymos, M.H.H. Stevens, E. Szoecs, H. Wagner, vegan: Community Ecology Package, 2016.

[54] S. Oreg, T. Katz-Gerro, Predicting proenvironmental behavior cross-nationally: values, the theory of planned behavior, and value-belief-norm theory, Environ. Behav. 38 (2006) 462-483.

[55] E. Ostrom, A diagnostic approach for going beyond panaceas, Proc. Natl. Acad. Sci. USA 104 (2007) 15181-15187.

[56] R. Pakenham, Land Tenure Among the Wahadimu at Chwaka, Zanzibar Island, Government Printer, South Africa, 1947.

[57] E. Pérez-Sánchez, J.F. Muir, Fishermen perception on resources management and aquaculture development in the Mecoacan estuary, Tabasco, Mexico, Ocean Coast. Manag. 46 (2003) 681-700.

[58] R.B. Pollnac, B.R. Crawford, Assessing Behavioral Aspects of Coastal Resource Use, Coastal Resources Center, University of Rhode Island, Narragansett, Rhode Island, 2000.

[59] R Core Team, R: A Language and Environment for Statistical Computing, R Foundation for Statistical Computing, Vienna, Austria, 2016.

[60] M. Reed, A. Evely, G. Cundill, I. Fazey, J. Glass, A. Laing, J. Newig, B. Parrish, C. Prell, C. Raymond, et al., What is social learning? Ecol. Soc. (2010) 15.

[61] J. Rehren, Modelling the Multispecies Fishery of Chwaka Bay, Zanzibar - Basis for Exploration of Use and Conservation Scenarios ((Ph.D. Thesis) Diss.), Univ. Bremen, Bremen, 2017.

[62] V. Reyes-García, A.L. Balbo, E. Gómez-Baggethun, M. Gueze, A. Mesoudi, P. Richerson, X. Rubio-Campillo, I. Ruiz-Mallén, S. Shennan, Multilevel processes and cultural adaptation: examples from past and present small-scale societies, Ecol.Soc.: J. Integr. Sci. Resil. Sustain. (2016) 21.

[63] A. Rivera, S. Gelcich, L. García-Flórez, J.L. Acuña, Heterogeneous management and conservation perceptions within the gooseneck barnacle co-management system in Asturias (N. Spain), Marine Policy 81 (2017) 229-235. 
[64] L.M. Ruttan, Sociocultural heterogeneity and the commons, Curr. Anthropol. 47 (2006) 843-853, https://doi.org/10.1086/507185.

[65] A. Saenz-Arroyo, C. Roberts, J. Torre, M. Carino-Olvera, R. Enríquez-Andrade, Rapidly shifting environmental baselines among fishers of the Gulf of California, Proc. R. Soc. Lond. B: Biol. Sci. 272 (2005) 1957-1962.

[66] M.R. Silva, P.F. Lopes, Each fisherman is different: taking the environmental perception of small-scale fishermen into account to manage marine protected areas, Mar. Policy 51 (2015) 347-355.

[67] P.E. Smaldino, The cultural evolution of emergent group-level traits, Behav. Brain Sci. 37 (2014) 243-254.

[68] M.R. Symonds, A. Moussalli, A brief guide to model selection, multimodel inference and model averaging in behavioural ecology using Akaike's information criterion, Behav. Ecol. Sociobiol. 65 (2011) 13-21.

[69] W.N. Venables, B.D. Ripley, Modern Applied Statistics with S, Fourth Edition, Springer, New York, 2002.

[70] T. Waring, M. Kline, J. Brooks, S. Goff, J. Gowdy, M. Janssen, P. Smaldino, J. Jacquet, A multilevel evolutionary framework for sustainability analysis, Ecol. Soc. (2015) 20.

[71] T.M. Waring, E. Tremblay, An evolutionary approach to sustainability science, Cliodynamics: J. Quant. Hist. Cult. Evol. 7 (2016) 119-167.

[72] F.R. Westley, O. Tjornbo, L. Schultz, P. Olsson, C. Folke, B. Crona, Ö. Bodin, A theory of transformative agency in linked social-ecological systems, Ecol. Soc. (2013) 18.

[73] G. Wilson, Community Resilience and Environmental Transitions, Routledge, London, 2012. 